\title{
Control of Verticillium Yellows in Chinese Cabbage by the Dark Septate Endophytic Fungus LtVB3
}

\author{
K. Narisawa, F. Usuki, and T. Hashiba
}

\begin{abstract}
First author: Department of Biological Sciences, University of Alberta, Edmonton, Alberta, T6G 2E9, Canada; first and second authors: Plant Biotechnology Institute Ibaraki Agricultural Center, Ago, Iwama, Nishi Ibaraki 319-0292 Japan; and third author: Laboratory of Plant Pathology, Faculty of Agriculture, Tohoku University, Sendai 981-8555, Japan.
\end{abstract} Accepted for publication 17 December 2003.

\begin{abstract}
Narisawa, K., Usuki, F., and Hashiba, T. 2004. Control of Verticillium yellows in Chinese cabbage by the dark septate endophytic fungus LtVB3. Phytopathology 94:412-418.

Three hundred forty-nine fungal endophytes were obtained from a total of 1,214 root segments of eggplant, melon, barley, and Chinese cabbage grown as bait plants in a mixed soil made up of samples from different forest soils in Alberta and British Columbia, Canada. Three of the 349 isolates, when inoculated in axenically reared Chinese cabbage seedlings grown in petri dishes, almost completely suppressed the effects of a postinoculated and virulent strain of Verticillium longisporum. Two isolates effective against the pathogen were Phialocephala fortinii, which had been obtained from the roots of eggplant and Chinese cabbage. The third isolate was a dark septate endophytic (DSE) fungus obtained from barley roots. Hyphae of $P$. fortinii grew along the surface of the root and formed microsclerotia on or in the epidermal layer. Hyphae of the DSE fungus heavily colonized root cells of the cortex. Seedlings grown for 1 week in
\end{abstract}

ABSTRACT the presence of the endophytes were then challenged with the Verticillium pathogen. In DSE-treated roots, some of cell walls in the epidermal and cortical layers showed cell wall appositions and thickenings, which appeared to limit the ingress of the pathogen into adjacent cells. Such marked host reactions were not observed in the root cells colonized by $P$. fortinii. Chinese cabbage preinoculated with the above endophytes and, for comparison, a previously reported disease-suppressive fungal endophyte, Heteroconium chaetospira, were transplanted into the field and disease symptoms were assessed. The DSE could most effectively inhibit the development of Verticillium yellows, with reductions in the percentages of external and internal disease symptoms of 84 and $88 \%$, respectively. The protective values against the disease are extremely high compared with those of other isolates. Most of the DSE-treated plants in the plots achieved marketable quality.

Additional keyword: cytology.
Verticillium yellows, caused by Verticillium longisporum Karapapa Stark in Chinese cabbage (Brassica campestris L.), are characterized by etiolation of leaves, browning of vascular bundles in roots and stems, and severe reduction in yield. It has become a serious soilborne disease in Japan since it was first observed in the Nagano prefecture in 1966 (15). Since then, the disease has become prevalent in other parts of Japan as well.

Control of the pathogen has been primarily by soil fumigants, including methyl bromide, in the past; however, these chemicals are serious atmospheric pollutants and their use need to be reduced. Commercial cultivars of Chinese cabbage that are resistant to other soilborne diseases, including clubroot caused by Plasmodiophora brassicae Woronin, have been accepted by growers, but no resistant cultivar has been developed for Verticillium yellows. Biocontrol methods have the potential for controlling the disease and reducing the use of chemical agents. To our knowledge, only one biocontrol study has been reported for the control of Verticillium yellows in Chinese cabbage. Narisawa et al. (8) found that the dematiaceous hyphomycete Heteroconium chaetospira (Grove) M. B. Ellis could colonize roots of the plant, mainly cortical cells, and suppress the disease in the field. $H$. chaetospira-treated plants displayed external symptoms of the disease and caused a maximum disease reduction of $60 \%$ under highinfestation conditions. This level of protection, however, may not be sufficient for growers, because the outer leaves of most treated

Corresponding author: K. Narisawa; E-mail address: knarisawa@agri.pref.ibaraki.jp

Publication no. P-2004-0308-01R

(c) 2004 The American Phytopathological Society plants showed slight yellowing. Therefore, it would be beneficial to find more effective biocontrol agents to control this disease. There is no effective method for the screening of biocontrol agents for disease control, mainly because typical symptoms of Verticillium yellows, including etiolation, are extremely difficult to develop under pot-cultured conditions. In fact, $H$. chaetospira was not originally screened to control Verticillium yellows but to control clubroot (9). Recently, Narisawa and Kawamata (6) reported an in vitro inoculation method of Chinese cabbage seedlings with $V$. longisporum that led to the development of symptoms on seedlings. With modifications, this method may be practical for the selection of effective fungal candidates able to suppress Verticillium yellows of Chinese cabbage as well.

We consider microorganisms that are able to colonize the rhizosphere and then enter, survive, or proliferate endophytically as potentially efficient biocontrol agents (12). We proposed the idea that there is a wide range of naturally occurring fungal root endophytes that may be able to suppress diseases in their host plants. Based on this idea, we previously obtained a suite of root endophytic fungi, including $H$. chaetospira and Phialocephala fortinii Wang \& Wilcox, that effectively suppressed Verticillium wilt in eggplant seedlings (7).

In this paper, we describe a screening method for endophytic fungal candidates that were effective in suppressing Verticillium yellows in host seedlings. We also provide the suppressive values of selected isolates and compare them with the previously reported fungal endophyte $H$. chaetospira under field conditions. The features or identities of the selected isolates and the disposition of endophytic hyphae of the fungi in roots of host seedlings are addressed in this paper. In addition, histological observations of the endophyte-treated Chinese cabbage roots postinoculated 
with the pathogen were examined to ascertain the mechanisms of the disease suppression.

\section{MATERIALS AND METHODS}

Host plant. Chinese cabbage cv. Shin-Riso (Nihon-norin Co., Tokyo, Japan), susceptible to Verticillium yellows, was used for all experiments.

Isolation of fungal endophytes from soil. Soil samples were collected from seven sites from July to September 1999 and 2000 in Alberta and British Columbia, Canada. From each site, three soil samples (approximately $200 \mathrm{ml}$ each) were collected at a depth of approximately $20 \mathrm{~cm}$, placed in polyethylene bags, and stored at $4^{\circ} \mathrm{C}$ for up to 1 month. Soil samples were combined and mixed with 2 liters of autoclaved potting soil (Altwin Distributions Inc., Alberta, Canada) to prepare a composite soil for baiting fungal endophytes according to Narisawa et al. (7).

To bait for root endophytic fungi, axenically grown seedlings of barley (Hordeum vulgare L. var. hexastichon Asch.), Chinese cabbage (B. campestris), eggplant (Solanum melongena L.), and melon (Cucumis melo L.) were transplanted to $200-\mathrm{ml}$ pots containing the composite soil (three seedlings per pot, three pots per plant species). Seedlings were incubated at 20 to $25^{\circ} \mathrm{C}$ under a 16-h photoperiod $\left(180 \mathrm{~mol} \mathrm{~m}^{-2} \mathrm{~s}^{-2}\right)$. After 2 months, the roots of each plant species from each series of replicate pots were cleaned and cut into $1-\mathrm{cm}$ segments. Thirty segments from each plant species were chosen at random for isolating fungi according to the methods described in Narisawa et al. (9). Briefly, this involved washing root segments three times in a $0.005 \%$ solution of Tween 20 and rinsing each sample three times with sterile distilled water (SDW). Segments were air dried and plated on nutrient agar containing $25 \mathrm{~g}$ of corn meal (infusion form, Difco) and $15 \mathrm{~g}$ of Bacto agar (Difco Laboratories, Detroit) per liter. Fungal isolates were identified based on morphology of sporulating structures or, in the case of nonsporulating fungi, grouped according to colony color.

Selection of fungal endophytes for the suppression of Verticillium yellows in petri dish-grown plants. Each fungal isolate was grown on oatmeal agar (OMA; $10 \mathrm{~g}$ of oatmeal and $18 \mathrm{~g}$ of Bacto agar), $1 \mathrm{~g}$ of $\mathrm{MgSO}_{4} \cdot 7 \mathrm{H}_{2} 0,1.5 \mathrm{~g}$ of $\mathrm{KH}_{2} \mathrm{PO}_{4}$, and $1 \mathrm{~g}$ of $\mathrm{NaNO}_{3}$ per liter in petri dishes $(55-\mathrm{mm}$ diameter) at room temperature (approximately $23^{\circ} \mathrm{C}$ ). After 2 weeks, three 1-day-old Chinese cabbage seedlings, grown in gnotobiotic conditions, were transplanted onto each fungal colony on the medium. Seedlings transplanted onto noninoculated medium were used as controls. Seedlings were incubated in a growth chamber at 20 to $25^{\circ} \mathrm{C}$ under a 16 -h photoperiod $\left(180 \mathrm{~mol} \mathrm{~m}^{-2} \mathrm{~s}^{-2}\right)$ for 1 week.

Inoculum of the pathogen $V$. longisporum (isolate Ver. 4, available from K. Narisawa) that had been isolated from diseased Chinese cabbage roots cultivated in naturally infested field soil at Chiyokawa, Ibaraki, Japan, was prepared by growing the fungus on OMA in petri dishes for 3 weeks at room temperature.

Seedlings grown for 1 week with and without individual endophytes were challenged with the pathogen. The seedlings with the agar medium were overlaid directly onto the fungal colony of the pathogen, kept in plastic trays (Sigma Chemical, St. Louis), and incubated in a growth chamber (as described previously). Disease symptoms were assessed 3 weeks after transplanting according to the disease index of Narisawa et al. (8) with slight modifications. External symptoms were visually rated among four classes: 0 (no foliar symptoms), 1 (slight yellowing of leaves, mostly near the edges), 2 (yellowing of leaves), and 3 (death of leaves). The number of plants in class 1 was multiplied by 10 , in class 2 by 60 , and in class 3 by 100, and the sum, including the number of plants in class 0 , was divided by the total number of plants in each treatment to give a numerical value, called the disease index. Symptoms of disease were noted from nine plants in three dishes. The experiment was repeated at least three times.
Examination of endophytic growth and host response. After disease symptoms were assessed, roots were recovered from Chinese cabbage seedlings inoculated with effective isolates, washed three times with SDW, and cut into segments of approximately $2 \mathrm{~cm}$. Root segments were then hand-sectioned with a razor blade and stained with $0.005 \%$ cotton blue in $50 \%$ acetic acid. Fifty root segments were randomly selected from each plant in each treatment and mounted on glass slides. Colonization patterns of the selected fungal endophytes in Chinese cabbage roots and host responses were observed under an Olympus BX50 microscope with UplanFI20 and 40/0.30 objectives (Olympus, Tokyo).

Inoculation of Chinese cabbage seedlings with fungal endophytes using soil and assessment of root colonization by fungal endophytes. Sets of seedlings with the effective endophytic fungal isolates were selected to measure the degree of root colonization by the inoculants. The endophyte-colonized plants were prepared as described by Usuki et al. (13), i.e., the inoculants were grown on medium ( $25 \mathrm{~g}$ of Difco corn meal (infusion form), $10 \mathrm{~g}$ of Difco malt extract, $2 \mathrm{~g}$ of Difco yeast extract, $15 \mathrm{~g}$ of Bacto agar, and 1 liter of water) in petri dishes (90-mm diameter) at room temperature. After 4 weeks, fungal colonies of each isolate were removed from the medium with a spatula and mixed with $50 \mathrm{ml}$ of SDW. Fungal mycelium was separated from the broth by filtering the broth through eight layers of sterile gauze. The mycelium remaining on the gauze was washed three times with SDW and macerated in a homogenizer with $200 \mathrm{ml}$ of a sterile liquid medium ( $1 \mathrm{~g}$ of glucose, $0.2 \mathrm{~g}$ of $\mathrm{MgSO}_{4} \cdot 7 \mathrm{H}_{2} \mathrm{O}, 1 \mathrm{~g}$ of $\mathrm{NaNO}_{3}, 0.2 \mathrm{~g}$ of $\mathrm{KCl}$, and $1 \mathrm{~g}$ of $\mathrm{KH}_{2} \mathrm{PO}_{4}$ per liter of water) to make a fungal suspension. This suspension was mixed with autoclaved peat moss $(200 \mathrm{~g})$ to obtain a final concentration of approximately $10^{4}$ hyphal segments per gram of dry soil and a $60 \%$ moisture content. Axenic, 1-day-old Chinese cabbage seedlings were transplanted to pots containing the soil inoculum. They were incubated in the growth chamber at 20 to $25^{\circ} \mathrm{C}$ under a $16-\mathrm{h}$ photoperiod for 3 weeks. After 3 weeks, the roots of 10 seedlings were randomly selected from each treatment and recovered. The recovered roots were cut into segments, and segments up to $5 \mathrm{~cm}$ in length were stained with $0.005 \%$ cotton blue in $50 \%$ acetic acid and observed under an Olympus BX50 microscope with UplanFI20/0.30 objectives to assess the degree of fungal colonization. Stained roots were examined along grid lines to estimate the percentage of colonization. Each grid cell was designated as either colonized or noncolonized (13). Colonization was determined as described previously.

Disease assessment under field conditions. Two experimental plots were set up to examine the effect of selected fungal endophytes on Verticillium yellows. The field experiments were conducted at Iwama, Ibaraki, Japan. Soils in both plots were haplic andosols derived from volcanic ash soil and humus. The soil $\mathrm{pH}$ was 5.3 and 5.5 in plots 1 and 2, respectively. Approximately 100 plants per treatment were transplanted into each plot.

To prepare the inoculum of the pathogen, $V$. longisporum was grown on potato dextrose agar (Difco Laboratories) in petri dishes (90-mm diameter) for 1 week at room temperature. Three mycelial plugs (approximately $5 \mathrm{~mm}^{2}$ ) from these plates were transferred into each of three 300-ml Erlenmeyer flasks containing $100 \mathrm{ml}$ of potato dextrose broth (Difco Laboratories). The pathogen was then cultured statically for 2 weeks at room temperature. Fungal mycelium was separated from the broth by filtering the culture through eight layers of sterile gauze. The mycelium remaining on the gauze was washed three times with SDW and macerated in $180 \mathrm{ml}$ of SDW in a homogenizer. The macerate was centrifuged at $1,700 \times g$ for $10 \mathrm{~min}$ by a swinging bucket rotor. To wash the macerate, it was resuspended in $180 \mathrm{ml}$ of SDW and centrifuged again. This process was repeated three times. The resulting suspension of conidia and hyphal segments was diluted with SDW to a concentration of $1 \times 10^{6}$ propagules $\mathrm{ml}^{-3}$ using a hemacytometer. 


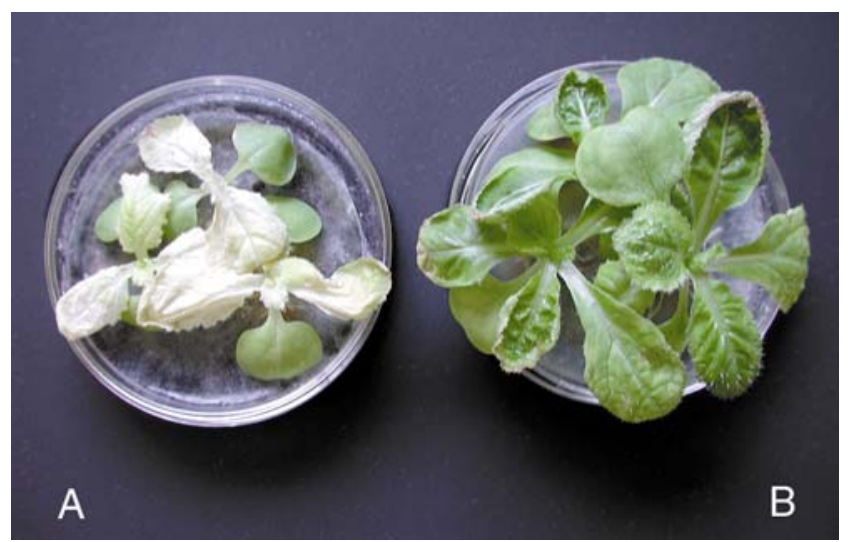

Fig. 1. The effect of the fungal endophyte (dark septate endophytic [DSE] taxon) on Verticillium yellows in petri dish-grown Chinese cabbage seedlings. Disease symptoms were assessed 3 weeks after transplanting. A, The foliage of control plant seedlings were extremely yellowed and severely damaged. B, The DSE-treated seedlings did not show typical external symptoms and appeared to be healthy.
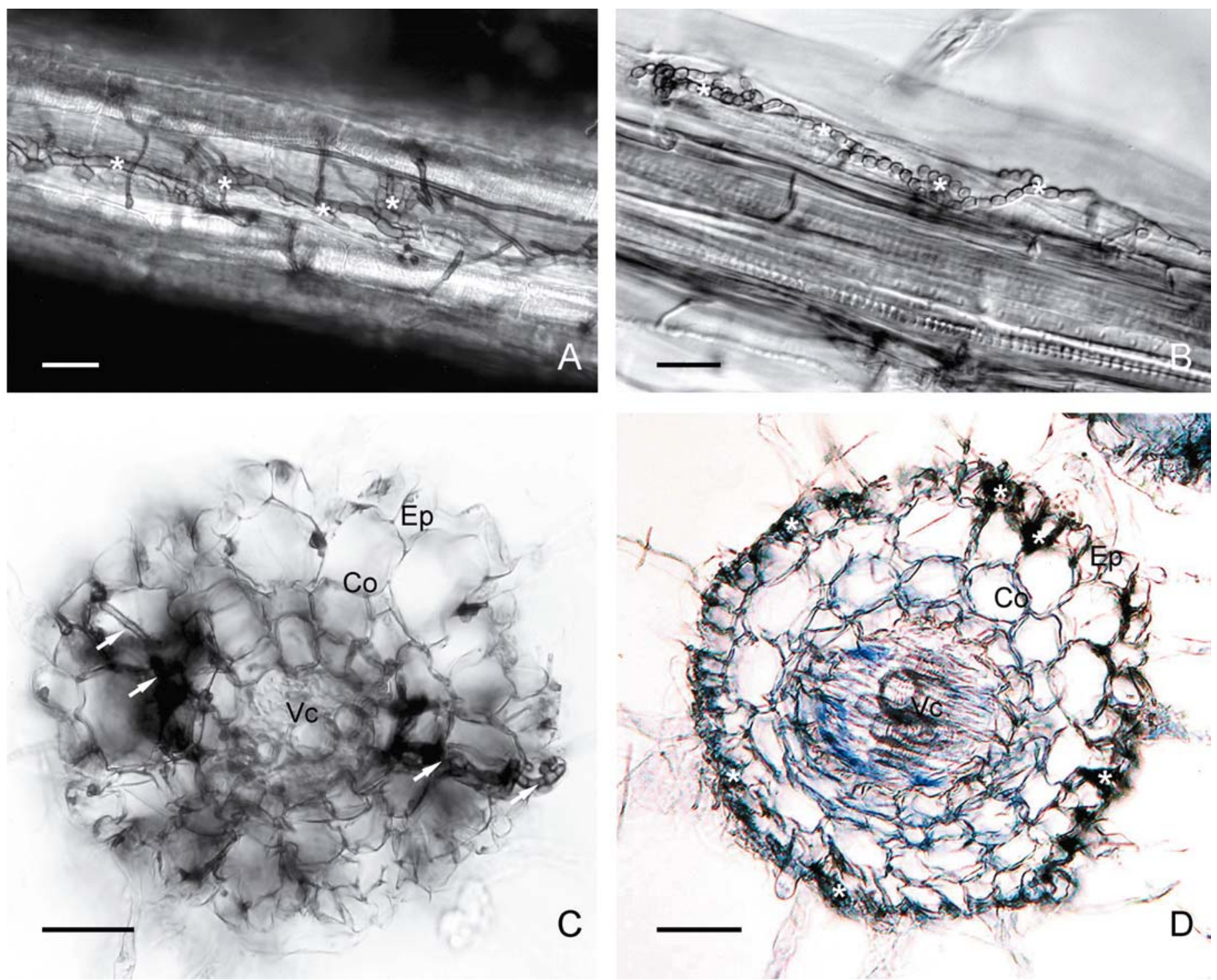

C
Chinese cabbage seedlings, grown with and without the endophytes for 3 weeks in peat moss, were challenged with the pathogen. The seedlings were approximately $7 \mathrm{~cm}$ tall and had five leaves. To inoculate the seedlings with the pathogen, root dip was accomplished by immersing the seedling roots in the suspension of the pathogen propagules at room temperature. After $1 \mathrm{~h}$, the inoculated seedlings were transplanted to the plots (in early September 2001). Disease symptoms were assessed 2 months after transplanting. In total, 40 plants in each treatment per plot were selected at random and classified. The severity of Verticillium yellows was reported across four classes based on both internal and external symptoms. External damage was evaluated using the following scale: $0=$ no external symptoms; 1 = slight yellowing, usually confined to outer leaves; $2=$ moderate yellowing on all leaves; and 3 = severe necrotic yellowing on all leaves. Vascular discoloration was evaluated according to the following scale: $0=$ no discoloration; 1 = browning localized below the hypocotyl level; 2 = browning of vessels but not of adjacent tissues; and $3=$ browning of both vessels and adjacent tissues. Then, the disease index was calculated as the sum of the products obtained as follows: in class $0(\times 0)$, in class $1(\times 10)$, in class $2(\times 30)$, and in

Fig. 2. Interactions between Chinese cabbage seedlings and two fungal endophytes (Phialocephala fortinii and the dark septate endophytic [DSE] taxon). A, Colonization of roots by P. fortinii with microsclerotia (asterisks) on or in host epidermal cells. B, Colonization of roots by the DSE taxon with dematiaceous, rounded hyphae (asterisks) on or in the host epidermal cells. C and D, Cross section of a Chinese cabbage root stained with $0.005 \%$ cotton blue in $50 \%$ acetic acid. The cortex (Co) consists of mostly three cell layers. Colonization by P. fortinii is limited to the inner cortical cells (C, arrows). Conversely, colonization by the DSE taxon is restricted to epidermal (Ep) and outer cortical cells $(\mathbf{D}$, asterisks). Vc $=$ vascular cylinder. Bars $=10 \mu \mathrm{m}$. 
class $3(\times 100)$. The products were then divided by the total number of plants.

Data analysis. An analysis of variance (ANOVA) was performed using the Abacus Concept, StatView procedure (Abacus Concept, Inc., Berkeley, CA). The proportion of diseased plants, mean weight, and percent reduction were analyzed for significance using an ANOVA followed by Fisher's protected least significant difference test. All percentage data were arcsine-transformed before analysis.

\section{RESULTS}

Effect of fungal endophytes on disease incidence in petri dish-grown plants. Three hundred forty-nine fungal endophytes were obtained from a total of 1,214 root segments of eggplant, melon, barley, and Chinese cabbage grown as bait plants in a mixed soil. Endophytic isolates belonging to $P$. fortinii were the most prevalent in all four hosts species. Other taxa, including $H$. chaetospira and variable white taxon (4), were recovered in much smaller numbers from all bait crop plants. Isolation frequencies differed among the taxa and depended on the species of bait plant. Thus, $40 \%$ of eggplant and $29.7 \%$ of Chinese cabbage root segments yielded all fungal taxa, respectively, whereas only $16.5 \%$ or less of the other plants, melon and barley, yielded them.

Most plants inoculated with ineffective isolates, once re-inoculated in axenically grown Chinese cabbage seedlings, and control plants showed extreme yellowing of leaves (Fig. 1A). Most of
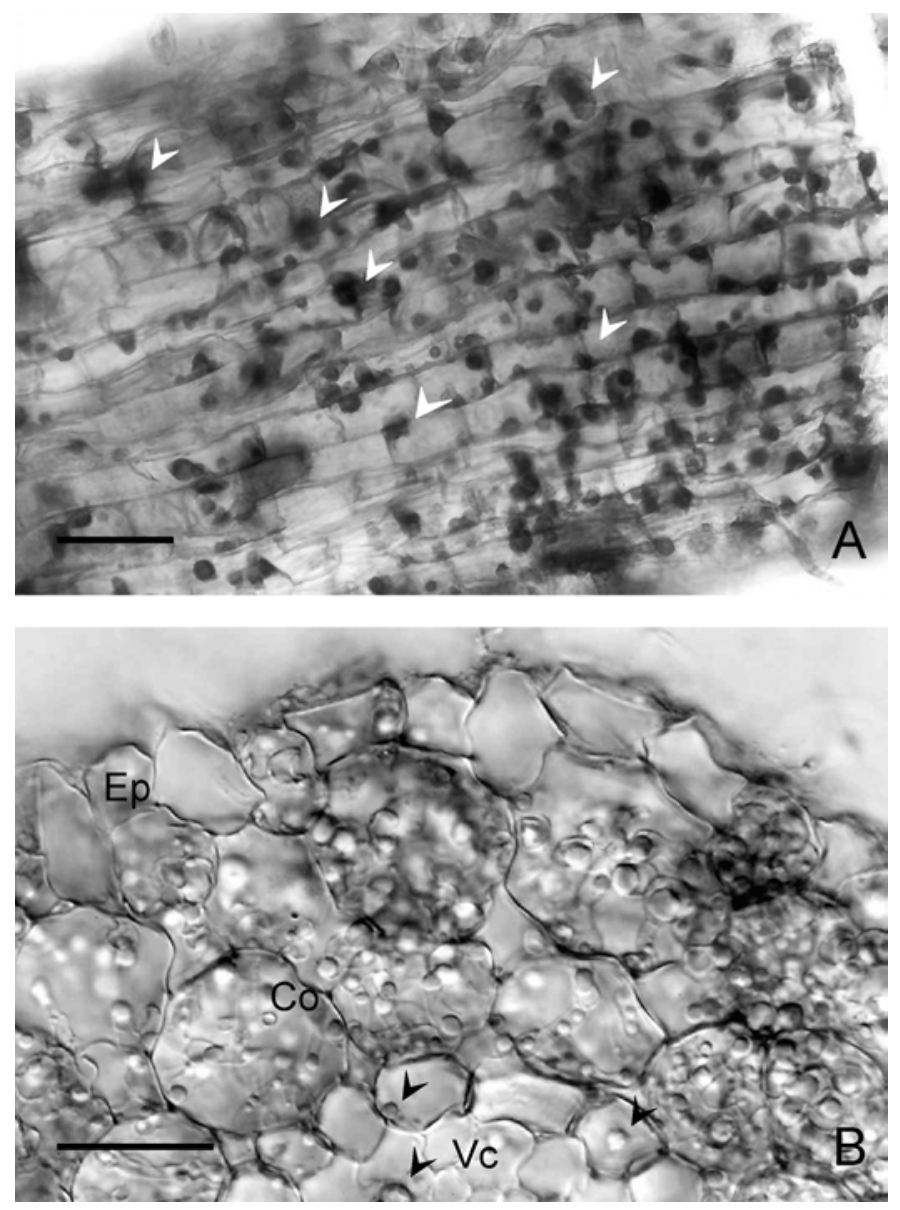

Fig. 3. The infection process of Verticillium longisporum in Chinese cabbage roots. A, Heavy fungal colonization by the pathogen on the root surface. Microsclerotia (arrows) of the pathogen on or in the host epidermal cells. B, Cross section of a Chinese cabbage root stained with $0.005 \%$ cotton blue in $50 \%$ acetic acid. Fungal colonization of the pathogen has reached the vascular cylinder (Vc) (arrows). Epidermal (Ep) and cortical (Co) cells were already colonized by fungal hyphae. Bars $=10 \mu \mathrm{m}$. these plants died subsequently. The mean index of external symptoms of these plants was 70.3. Alternatively, 3 of the 349 isolates (LtPE2, J2PC2, and LtVB3) almost completely suppressed the effects of a postinoculated and virulent strain of $V$. longisporum. These seedlings did not show typical external disease symptoms on leaves, including etiolation (Fig. 1B). The mean disease symptom indices of Chinese cabbage seedlings inoculated with LtPE2, J2PC2, and LtVB3 were 8.3, 6.2, and 9.7, respectively.

Two of the effective isolates (LtPE2 and J2PC2) were identified as $P$. fortinii and had been obtained from eggplant and Chinese cabbage roots, respectively. The third isolate (LtVB3) originated from barley roots and produced sterile, dark septate mycelium in culture and belonged to the dark septate endophytic (DSE) group of fungi. DSE taxa are dematiaceous fungi that occur with some regularity in the roots of apparently healthy plants, where they usually form distinctive intracellular structures or colonization patterns (5).

Growth of root endophytes in root tissues of Chinese cabbage and resistance reactions of the host. The roots inoculated with the three effective fungal isolates were stained with $0.005 \%$ cotton blue to examine the degree of colonization. Hyphae of both isolates of $P$. fortinii and the DSE taxon extensively colonized the root of Chinese cabbage seedlings without causing any visible external symptoms. Hyphae of $P$. fortinii grew along the surface of the root and formed microsclerotia on or in the epider-
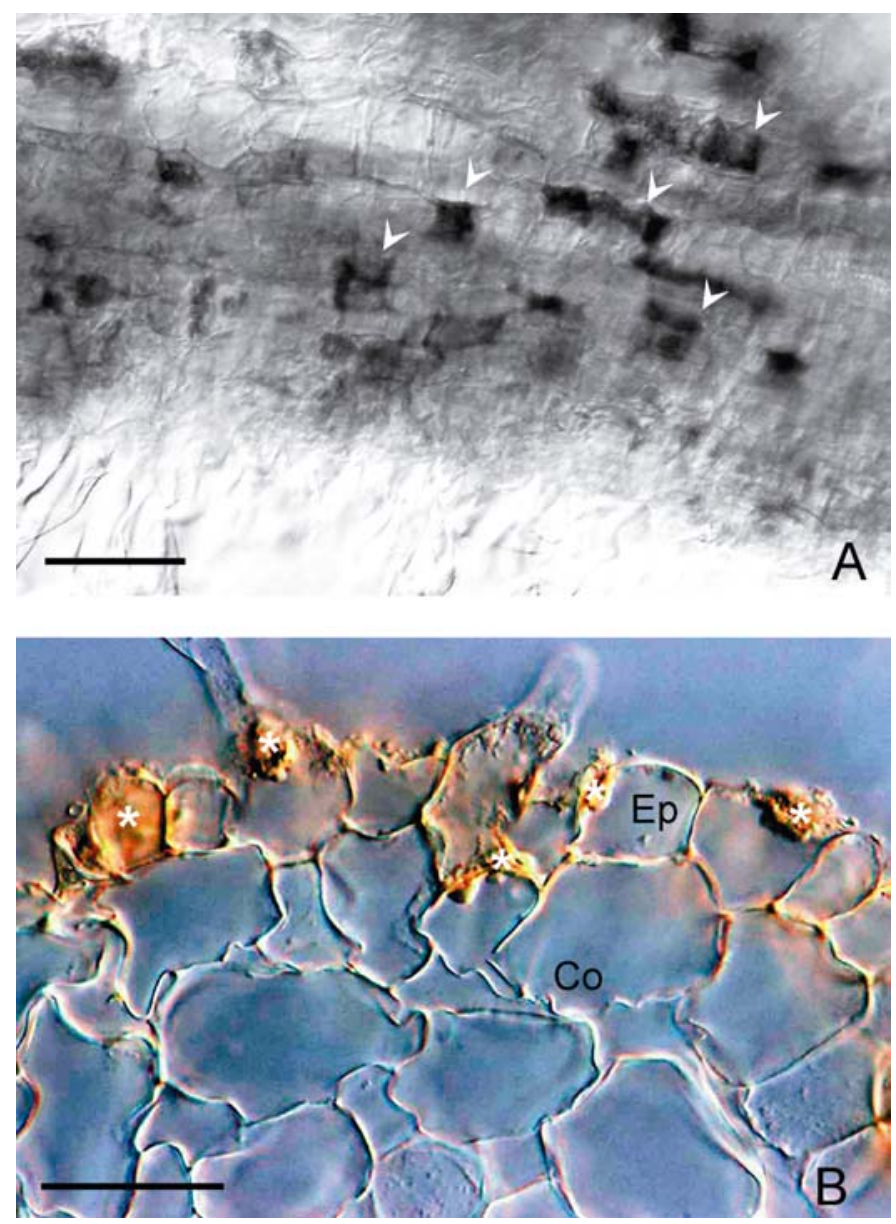

Fig. 4. Histological observation of dark septate endophytic fungus (DSE)treated Chinese cabbage roots postinoculated with Verticillium longisporum. A, Most of the epidermal cells of the host root reacted defensively and showed a light brown color against the ingress of the pathogen (arrows). B, Root cross section stained with $0.005 \%$ cotton blue showing a light brown color, wall appositions, and thickenings of epidermal (Ep) and cortical cells (Co) (asterisks). Bars $=10 \mu \mathrm{m}$. Note that no fungal hyphae of the pathogen were seen in these roots. A host defensive reaction may prevent the colonization of root cells by the pathogen. 
mal layer (Fig. 2A). Hyphae of the DSE taxon heavily colonized some root cortical cells (Fig. 2B). These fungal taxa exhibited unique differences in their colonization morphology, i.e., $P$. fortinii produced dematiaceous, lobed hyphae and sclerotic cells, whereas the DSE taxon formed dematiaceous, rounded hyphae in root cells (Fig. 2A and B).

Light microscopy of cross sections of colonized Chinese cabbage roots showed that the intercellular, pigmented hyphae of both isolates of $P$. fortinii extended into the inner cortical cells and formed irregularly lobed, rounded, thick-walled cells, but they were not present in the vascular cylinder (Fig. 2C). Conversely, hyphae of the DSE taxon colonized epidermal cells intra-
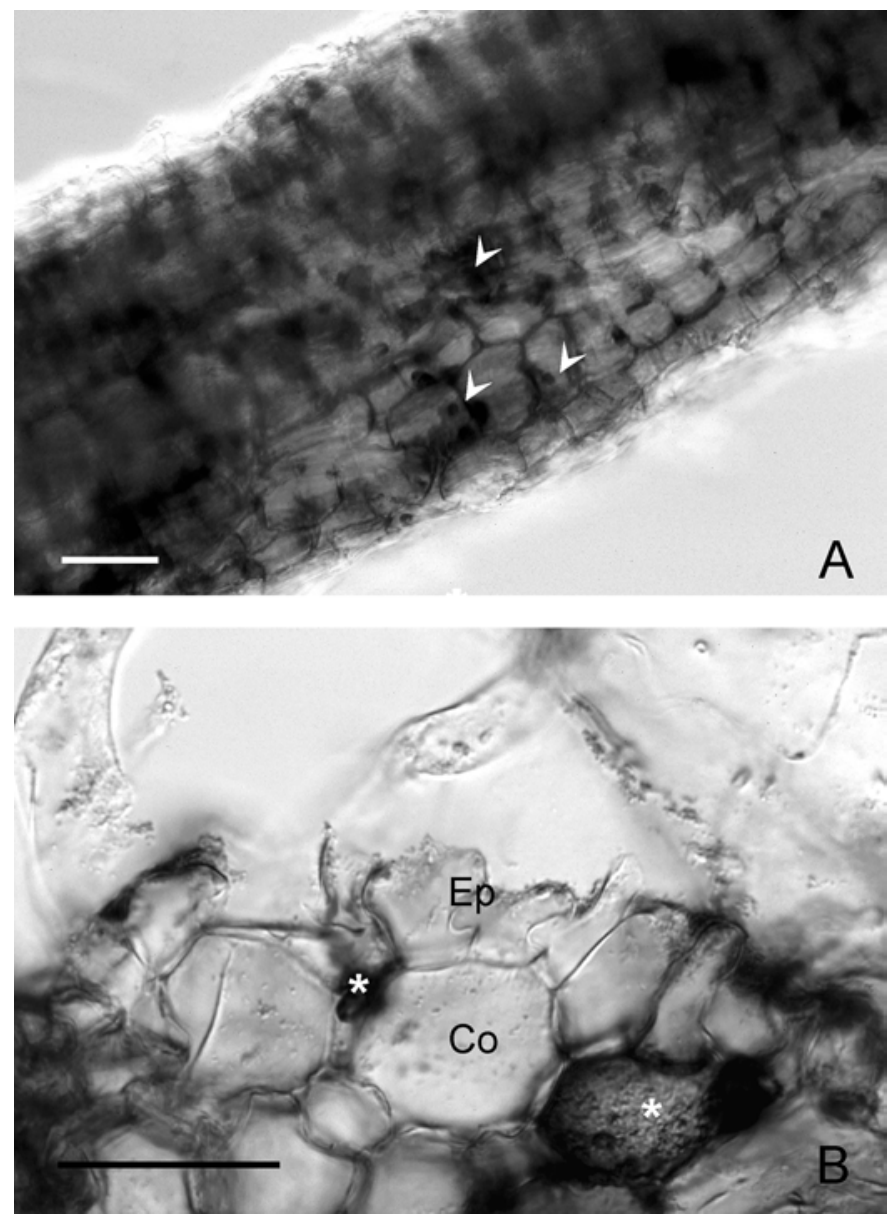

Fig. 5. Histological observation of Phialocephala fortinii-treated Chinese cabbage roots postinoculated with Verticillium longisporum. A, Some of the epidermal and cortical root cells of the host reacted defensively and showed a dark gray to black color against the ingress of the pathogen (arrows). B, Root cross section stained with $0.005 \%$ cotton blue showing a dark gray to black color, wall appositions, and thickenings of some epidermal (Ep) and cortical (Co) cells (asterisks). Bars $=10 \mu \mathrm{m}$. cellularly; however, the ingress of its hyphae was mostly limited to the epidermal layer. Hyphae were rare in the outer cortical cells and altogether absent from middle or inner cortical cells (Fig. 2D). No visible signs of the host reactions were seen in the root cells colonized by $P$. fortinii and the DSE taxon.

Seedlings were grown in vitro with and without the endophytes for 1 week before they were challenged with the pathogen. Two weeks after inoculation with the pathogen, roots inoculated with the endophytes showed no visible disease symptoms. These roots and those of the control plants were stained with $0.005 \%$ cotton blue and examined mainly for responses of the host plants to the infection by the pathogen. In roots of control plants, hyphae of the pathogen heavily colonized the surface of the root and formed typical black sclerotia on or in the epidermal layer (Fig. 3A). Subsequently, hyphae of the pathogen colonized the epidermal and cortical cells of the host root. Accordingly, most root cells, including those of the vascular cylinder, were colonized by the pathogen (Fig. 3B). No host resistance reaction occurred in the cells of the control roots. In the DSE taxon and $P$. fortinii-treated roots, any morphological structures of the pathogen previously mentioned were absent (Figs. 4A and 5A). Additionally, light microscopy observations, particularly using thin sections of the root segments inoculated with the DSE taxon, revealed marked changes mostly in the cells of the epidermal and cortical root tissues. Most of cell walls in this region were light brown and had cell wall appositions and thickenings (Fig. 4A and B). Such distinct host reactions were not observed in the root segments colonized by $P$. fortinii (Fig. 5A and B). However, localized hypersensitive-like defense reactions in host roots occurred in some of the root cortical cells as well (Fig. 5B, asterisk). These reactions appeared to restrict the ingress of the pathogen into adjacent root cells of the host plant.

Frequency of root colonization of Chinese cabbage by selected fungal isolates. The roots of 3 -week-old seedlings grown in pots with mixed soil with and without the three fungal isolates were recovered and their percentage of root colonization was estimated using the grid sheet method (13). The frequencies of root colonization by the two isolates of $P$. fortinii and the isolate of the DSE taxon were $66.7,76.7$, and $72.3 \%$, respectively. No fungal colonization of root cells was observed in control plants.

Effect of selected isolates on Verticillium yellows under field conditions. Chinese cabbage seedlings inoculated with the three selected endophytes and $H$. chaetospira were transplanted into two field plots. Disease symptoms and proportions of diseased plants were assessed 2 months after transplanting (Table 1). In these plots, the leaves of all control plants turned bright yellow and the vascular tissues of taproots and stems of most control plants turned dark brown.

$H$. chaetospira-treated plants significantly reduced the proportion of diseased plants and external and internal symptoms of Verticillium yellows compared with that of control plants, which represented a 46,45 , and $53 \%$ reduction in the disease, respectively $(P=0.05)$ (Table 1$)$. Most plants showed slight yellowing, usually confined to the outer leaves of the heads, but a few plants

TABLE 1. Effects of three selected fungal isolates and Heteroconium chaetospira on the incidence of Verticillium yellows in the field

\begin{tabular}{|c|c|c|c|c|}
\hline \multirow[b]{2}{*}{ Treatment } & \multirow{2}{*}{$\begin{array}{c}\text { Proportion of } \\
\text { diseased plants }(\%)\end{array}$} & \multicolumn{2}{|c|}{ Disease index $(\% \text { reduction })^{\mathrm{z}}$} & \multirow[b]{2}{*}{ Mean weight $(\mathrm{g})$} \\
\hline & & External symptoms & Internal symptoms & \\
\hline Phialocephala fortinii (J2PC2) & $83 \mathrm{a}$ & $74(-45 a)$ & $72(-6 b)$ & $1,130 \mathrm{a}$ \\
\hline P. fortinii (LtPE2) & $90 \mathrm{a}$ & $79(-55$ a) & $90(-32 a)$ & $1,034 \mathrm{a}$ \\
\hline Dark septate endophytic fungus (LtVB3) & $25 \mathrm{c}$ & $8.3(84 d)$ & $8.3(88 \mathrm{~d})$ & $1,973 \mathrm{~b}$ \\
\hline H. chaetospira $(\mathrm{H} 4007)$ & $50 \mathrm{~b}$ & $28(45 \mathrm{c})$ & $32(53 \mathrm{c})$ & $1,465 \mathrm{a}$ \\
\hline Control & $92 \mathrm{a}$ & $51(0 \mathrm{~b})$ & $68(0 \mathrm{~b})$ & $933 \mathrm{a}$ \\
\hline LSD value & 24 & 26 & 20 & 571 \\
\hline
\end{tabular}

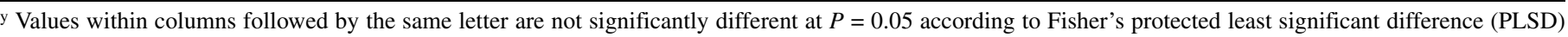
test.

${ }^{\mathrm{z}}$ Percent reduction $=100-($ inoculated value for disease index $/$ control value $) \times 100$. 
had moderate yellowing on all leaves. Chinese cabbage seedlings inoculated with $H$. chaetospira in situ had fresh weights approximately 1.5 times the weight of uninoculated controls.

Plants inoculated with the DSE taxon displayed proportions of diseased plants and external and internal symptoms of the disease dramatically that were significant lower than that of control plants, representing a 73, 84, and $88 \%$ reduction in the disease, respectively $(P=0.05)$ (Table 1$)$. Proportion of diseased plants and disease symptoms also were reduced relative to the $H$. chaetospira-treated plants $(P=0.05)$. Morphologically, most of the Chinese cabbage seedlings inoculated with the DSE taxon were healthy and had no external symptoms of the disease, achieving over $80 \%$ marketable quality. Chinese cabbage inoculated with the DSE taxon in situ had fresh weights approximately two times the weight of control plants under these conditions of disease pressure. Their weights differed significantly from those of control plants $(P=0.05)$ (Table 1$)$.

In contrast, both isolates of $P$. fortinii were not effective against the disease (Table 1). Many plants inoculated with $P$. fortinii were severely damaged and did not form compact heads, even by harvest time. The disease indices for external symptoms of yellows with J2PC2 and LtPE2 were actually higher than that of the control plants, indicating increased disease with the combination of $P$. fortinii and $V$. longisporum. The vascular tissues of taproots and stems of damaged plants turned dark brown to black and the indices of internal symptoms with J2PC2 and LtPE2 also were higher than that of the control plants (Table 1). Chinese cabbage inoculated with both isolates of $P$. fortinii in situ had fresh weights almost the same as the weight of uninoculated controls.

\section{DISCUSSION}

The new potential agent of biological control, the DSE taxon, could effectively inhibit the development of Verticillium yellows, even in situ. The percentage of external and internal symptoms of the disease reduction in the field was 84 and $88 \%$, respectively, and the protective values against the disease were significantly higher compared with those of other fungal endophytes, including $H$. chaetospira and $P$. fortinii. Most of the DSE-treated plants in the Verticillium yellows plots achieved marketable quality as a result of the protection by the DSE taxon.

We previously reported that the appropriate growth conditions in plant nursery settings, including suitable nutrient and carbon concentrations, were developed to ensure the formation of the symbiotic association between $H$. chaetospira and Chinese cabbage (13). The highest frequency of colonization (75\%) was attained when peat moss amended with $0.1 \%$ glucose was selected as the nursery soil. Under these conditions, fungal hyphae developed well intracellularly in root cortical cells, none of the inoculated plants showed any typical pathogenic symptoms, and plants attained a marketable quality (13). In the current study, using the selected nursery soil, the frequencies of root colonization by the two isolates of $P$. fortinii and the isolate of the DSE taxon were $66.7,76.7$, and $72.3 \%$, respectively. The colonization rates were high enough compared with a previous report (13). Therefore, the nursery method is broadly and practically useful for developing the formation of the symbiotic association between the DSE taxon and host plants.

External symptoms associated with Verticillium yellows had been extremely difficult to develop in vitro. In the current study, the petri dish-grown plants infected with the pathogen consistently showed extremely yellowed leaves and most plants died within 3 weeks. Thus, our new method of screening for biocontrol agents was highly reproducible and it readily differentiated diseased from protected plants. Using the petri dish-grown plant system, we were able to select three isolates (belonging to $P$. fortinii and the DSE group of fungi) that were effective against the pathogen. These agents can be isolated and selected with relative ease usually within 5 weeks. Furthermore, by using petri dishgrown plants, we could easily examine the disposition of endophytic hyphae within host roots and the host responses against the ingress of the pathogen.

In situ, host plants inoculated with the DSE taxon were not damaged. In contrast, $P$. fortinii-treated plants were severely damaged. In DSE-treated host roots, marked host reactions, mainly in most of the epidermal and cortical cells, against the ingress of the pathogen were common. Conversely, broad host defense reactions were not visible in the root cells inoculated with the two $P$. fortinii isolates. The finding of the broad defense reactions, which appeared as brown, thick, cell wall modifications, indicate that host cells had received a "signal" to protect themselves by producing antifungal substances (10). In addition, parameters of the plant defense response associated with the cell wall modifications, including secondary metabolite production and pathogenesisrelated proteins accumulation, have been reported (1). Furthermore, not only the concentrations of the defense metabolites, but also other parameters of the plant defense response, including phenylalanine ammonia-lyase and $\mathrm{H}_{2} \mathrm{O}_{2}$, have been detected near endophytic infections (11). These plant defense responses are associated with cell wall modifications. The complete mechanism of the disease suppression in the Chinese cabbage root-DSE interaction remains unknown and requires further study. However, since biocontrol mechanisms commonly target a number of points in the developmental series of a pathogen, the mechanisms of the suppression of Verticillium wilt may involve both indirect and direct interactions in or on host roots. From our observations and previous findings, it is possible that one of the mechanisms in the success of controlling Verticillium yellows of Chinese cabbage lies in the fact that DSE fungi indirectly protect plant tissues underlying or neighboring invaded areas by acting as mechanical barriers capable of preventing infections by postinoculated virulent strains of pathogens.

A previously reported Japanese isolate of $P$. fortinii, once reinoculated in eggplant seedlings, suppressed the effects of a postinoculated and virulent strain of Verticillium sp. in vitro (7). However, the role in the suppression of the effects of root pathogens by $P$. fortinii in situ has not been demonstrated prior to this work. In the current in situ study, $P$. fortinii-treated Chinese cabbage seedlings were severely damaged compared with control plants, as can be seen in the disease indices. It appears that $P$. fortinii and the pathogen act synergistically to parasitize the roots of its host plant in situ. In fact, it has previously been reported that $P$. fortinii can be weakly pathogenic, depending on environmental conditions, the host species, and the strain of the fungus $(14,16)$. However, the ecological behavior or relationship of $P$. fortinii with host plants, e.g., either symbiotic or parasitic, remains unclear. In addition, the other effects of $P$. fortinii-treated plants on the incidence of Verticillium yellow were similar to those in control plants (proportion of diseased plants and mean weights). Additional trials under different growth conditions may indicate if $P$. fortinii acts synergistically with pathogens to parasitize the roots of host plants.

Generally, fungi belonging to the DSE group are assumed to have a wide host range. For example, Leptodontidium orchidicola de Hoog, Piriformospora indica Verma, Verma, Rexer, Kost et Franken gen. nov., and $P$. fortinii have been shown to grow in a wide range of hosts $(2,3,5)$. H. chaetospira also is reported to be able to colonize the roots of plants, representing eight plant families, and consequently has a wide host range as well (8). In the present study, an isolate of a DSE taxon originally obtained from barley roots was able to colonize Chinese cabbage roots and suppress the development of Verticillium yellows, even in situ. Thus, it may have a wide host range as well. Endophytic fungi are known to induce strong antagonistic responses in host plants (11). These responses may be sufficient to provide resistance to different species of pathogens that otherwise penetrate tissues by evad- 
ing hosts defense mechanisms. The wide host range and broad applicable target diseases indicate that DSE taxa may have considerable potential for controlling other wilt diseases of different host plants, including those caused by species of Fusarium on tomato and melon.

\section{ACKNOWLEDGMENTS}

Part of this work was supported by a Japan Science and Technology Corporation Overseas Research Fellowship to K. Narisawa. We thank R. S. Currah, Department of Biological Sciences, University of Alberta, Edmonton, Alberta, Canada, for valuable suggestions and support for this project; and M. N. Thormann, Natural Resources Canada, Canadian Forest Service, Northern Forestry Centre, Edmonton, Alberta, Canada, for critically reviewing the manuscript.

\section{LITERATURE CITED}

1. Benhamou, N., and Garand, C. 2001. Cytological analysis of defenserelated mechanisms induced in pea root tissues in response to colonization by nonpathogenic Fusarium oxysporum Fo47. Phytopathology 91:730-740.

2. Fernando, A. A., and Currah, R. S. 1996. A comparative study of the effects of the root endophyte Leptodontidium orchidicola and Phialocephala fortinii (Fungi imperfecti) on the growth of some subalpine plants in culture. Can. J. Bot. 74:1071-1078.

3. Franken, P., Butehorn, B., and Verma, A. 1998. Piriformospora indica, a cultivable root cell-infecting fungus promotes the growth of a broad range of plant species. Page 65 in: Proc. 2nd Int. Congress of Mycorrhiza.

4. Hambleton, S., and Currah, R. S. 1996. Fungal endophytes from the roots of alpine and boreal Ericaceae. Can. J. Bot. 75:1570-1581.

5. Jumpponen, A., and Trappe, J. M. 1998. Dark septate endophytes: A review of facultative biotrophic root-colonizing fungi. New Phytol. $140: 295-310$
6. Narisawa, K., and Kawamata, H. 2002. In vitro development of disease symptoms of Verticillium wilt in Chinese cabbage seedlings. Annu. Rep. Ibaraki Plant Prot. Soc. 41:56-58.

7. Narisawa, K., Kawamata, H., Currah, R. S., and Hashiba, T. 2002. Suppression of Verticillium wilt in eggplant by some fungal root endophytes. Eur. J. Plant Pathol. 108:103-109.

8. Narisawa, K., Ohki, T., and Hashiba, T. 2000. Suppression of clubroot and Verticillium yellows in Chinese cabbage in the field by the root endophytic fungus, Heteroconium chaetospira. Plant Pathol. 49:141-146.

9. Narisawa, K., Tokumasu, S., and Hashiba, T. 1998. Suppression of clubroot formation in Chinese cabbage by root endophytic fungus, Heteroconium chaetospira. Plant Pathol. 47:206-210.

10. Scalet, M., Crivaletto, E., and Mallardi, F. 1989. Demonstration of phenolic compounds in plant tissues by an osmium-iodide post-fixation procedure. Stain Technol. 64:273-290.

11. Schulz, B., Rommert, A.-K., Dammann, U., Aust, H.-J., and Strack, D. 1999. The endophyte-host interaction: A balanced antagonism? Mycol. Res. 103:1275-1283.

12. Tjamos, E. 2000. Strategies in developing methods and applying techniques for the biological control of Verticillium dahliae. Pages 227-231 in: Advances in Verticillium: Research and Disease Management. E. C. Tjamos, R. C. Rowe, J. B. Heale, and D. R. Fravel, eds. The American Phytopathological Society, St. Paul, MN.

13. Usuki, F., Narisawa, K., Yonezawa, M., and Hashiba, T. 2002. An efficient inoculation method for colonization of Chinese cabbage seedlings by the root endophytic fungus Heteroconium chaetospira. J. Gen. Plant Pathol. 68:326-332.

14. Wang, C. J. K., and Wilcox, H. E. 1985. New species of ectendomycorrhizal and pseudomycorrhizal fungi: Phialophora finlandia, Chloridium paucisporum and Phialocephala fortinii. Mycologia 77:951-958.

15. Watanabe, T., Ozawa, M., and Sakai, R. 1973. A new disease of Chinese cabbage caused by Verticillium albo-atrum and some factors related to the incidence of the disease. Ann. Phytopathol. Soc. Jpn. 39:344-350.

16. Wilcox, H. E., and Wang, C. J. K. 1987. Mycorrhizal and pathological associations of dematiaceous fungi in roots of 7-month-old tree seedlings. Can. J. For. Res. 17:884-889. 